\title{
Phenolic Constituents from the Stems of Morus nigra and their $\alpha$-Glucosidase Inhibitory Activities
}

\author{
Ling-Ling Wang ${ }^{1}$ Liang-Jin Xu ${ }^{1}$ Meng-Jie Ma ${ }^{1}$ Chun-Yue Huang ${ }^{1}$ Tong Wu ${ }^{1} \quad \mathrm{Xiao} \mathrm{Hu}^{1,2^{*}}$ \\ ${ }^{1}$ State Key Laboratory of New Drug and Pharmaceutical Process, \\ Shanghai Institute of Pharmaceutical Industry, China State Institute \\ of Pharmaceutical Industry, Shanghai, People's Republic of China \\ 2 Shanghai Xinshengyuan Pharmaceutical Co., Ltd., Shanghai, \\ Address for correspondence Xiao Hu, PhD, Shanghai Institute of \\ Pharmaceutical Industry, 285 Gebaini Road, Shanghai 201203, \\ People's Republic of China (e-mail: xjtuyxhx@126.com).
}

People's Republic of China

Pharmaceut Fronts 2021;3:e8-e12.
Abstracts
Keywords
- Moraceae
- Morus nigra
- sanggenon-type flavanone
- nigragenon $\mathrm{F}$
- $\alpha$-glucosidase

A new sanggenon-type flavanone, nigragenon $F(1)$, together with 11 known compounds, trans-resveratrol (2), (E)-4-isopentenyl-3,5,2',4'-tetrahydroxystilbene (3), notabilisin $E(4)$, notabilisin $A(5)$, morusin (6), petalopurpurenol (7), 8-geranyl-5,7dihydroxycoumarin (8), 2,4-dihydroxybenzaldehyde (9), 4-ethoxy-2,6-dihydroxybenzoic acid (10), 3-hydroxy-4-methoxybenzaldehyde (11), and 4-hydroxybenzaldehyde (12), were isolated from the stems of Morus nigra. Compound 10 was a new natural product, compounds $3,4,7$, and 8 were reported from the Morus genus for the first time. All of the isolated compounds were evaluated for their $\alpha$-glucosidase inhibition activity. Among them, six compounds showed obvious inhibitory effects against $\alpha$ glucosidase with $\mathrm{IC}_{50}$ values ranging from 1.24 to $19.00 \mu \mathrm{mol} / \mathrm{L}$.

\section{Introduction}

As a metabolic chronic disease, diabetes has severely affected people's health. Evidence suggested that $\alpha$-glucosidase inhibitors, such as acarbose, miglitol as well as voglibose, can lower the glucose levels in plasma by delaying the absorbance of carbohydrates, and are used clinically to treat diabetes; however, they also bring adverse reactions such as abdominal pain, flatulence, and diarrhea. ${ }^{1}$ Thus, the discovery of natural, side-effect-free, and effective $\alpha$-glucosidase inhibitors from widely sourced medicinal plants are of important value for the treatment of diabetes.

Hyperglycemia is the major symptom of diabetes. It is well known that Morus plants are famous for their antihyperglycemia effects, and has received much attention in diabetes treatment. The isolated alkaloids from Morus plants, such as 1-deoxynojirimycin, and phenolic compo-

received

February 2, 2021

accepted

April 30, 2021
DOI https://doi.org/

10.1055/s-0041-1730957. ISSN 2628-5088. nents have demonstrated antidiabetes activity by exhibiting potent $\alpha$-glucosidase inhibitory activity. ${ }^{2,3}$ Thus, Morus plants may be a natural source for drug discovery for diabetes therapy.

Morus nigra Linn., as a deciduous shrub or tree, belongs to the Morus genus (Moraceae). The plant of M. nigra was introduced from western Iran in the 16th century and mainly distributed in southern Xinjiang province, China. ${ }^{4}$ Our previous program for screening antidiabetic bioactive substances has afforded a series of active compounds from M. nigra. ${ }^{5-7}$ As a continuous study, this research provided 12 compounds (1-12), including a new sanggenon-type flavanone (1) and a new natural product (10). All of them were evaluated for their $\alpha$-glucosidase inhibition activity, and six compounds showed significant inhibitory activity with $\mathrm{IC}_{50}$ values ranging from 1.24 to $19.00 \mu \mathrm{mol} / \mathrm{L}$. Our article provided novel potential compounds for the treatment of diabetes in the future.

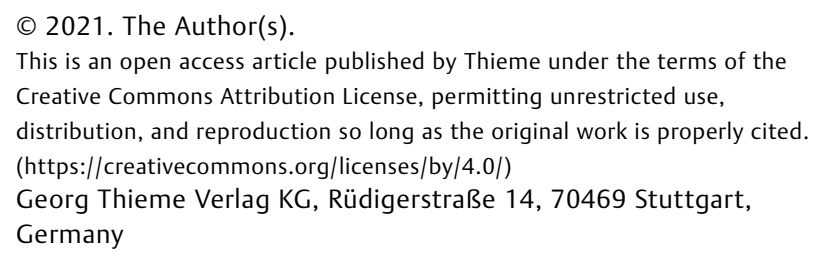




\section{Materials and Methods}

\section{General Methods}

Ultraviolet (UV) spectra were collected using a UV-2500 PC instrument (Shimadzu Corporation, Japan). Mass spectrometry was determined on a Waters Xevo G2-XS-Q-TOF. Nuclear magnetic resonance (NMR) spectra were recorded on a Bruker AV III instrument. Electronic circular dichroism spectra were obtained using a JASCO-810 spectropolarimeter. Silica gel (200-300 mesh, Qingdao Haiyang Chemical Co, Ltd.), Sephadex LH-20 (GE Healthcare, Sweden), and RP-C18 (YMC Co., Ltd., Japan) were used for column chromatography (CC). Thin layer chromatography was performed on silica gel HF254 plates using $10 \% \mathrm{H}_{2} \mathrm{SO}_{4}$ in ethanol (v/v) spray reagents followed by heating. Semipreparative high-performance liquid chromatography (HPLC) was carried out on a LC3050N HPLC using a C18 column $(10 \times 250 \mathrm{~mm}, 5 \mu \mathrm{m}$, Waters Corporation, United States) and characteristic UV absorption at $210 \mathrm{~nm}$. Reagents were of analytical reagent grade (Sinopharm Chemical Reagent Co., Ltd., Shanghai, China) except for acetonitrile and methanol which were of chromatographic grade.

\section{Plant Materials}

The stems of M. nigra L. (Moraceae) were collected from Hetian town, in the Xinjiang province of China in September 2016. The plant was identified by Prof. Tong Wu, who comes from China State Institute of Pharmaceutical Industry, China. A voucher specimen (No. 201609001) was deposited in our department.

\section{Extraction and Isolation}

The dried and powered stems of $M$. nigra (15 kg) were extracted twice with $90 \%$ aqueous EtOH under hot reflux (1.5 hours each time). The concentrated extract was suspended in water and partitioned successively with petroleum ether (PE), dichloromethane (DCM), ethyl acetate (EtOAc), and $n$-butanol. The crude extracts of DCM portion $(120 \mathrm{~g})$ and EtOAc portion $(80 \mathrm{~g})$ were mixed and then subjected to silica gel $\mathrm{CC}$, eluted with $\mathrm{CH}_{2} \mathrm{Cl}_{2}-\mathrm{CH}_{3} \mathrm{OH}(80: 1 \rightarrow$ $1: 1$ ) to obtain six fractions (Fr.A-Fr.F). Fr.A (42.5 g) was purified by silica gel CC (PE-acetone, $15: 1 \rightarrow 1: 1)$ to obtain 18 subfractions (Fr.A-1-Fr.A-18). Fr.A-8 (13.3 g) was decolored with HP-20 macroporous-absorbing resin eluted with EtOH to get a fraction (Fr.A-8-1). Fr.A-8-1 was further separated by $\mathrm{CC}$ successively over Sephadex $\mathrm{LH}-20\left(\mathrm{CH}_{2} \mathrm{Cl}_{2}-\right.$ $\left.\mathrm{CH}_{3} \mathrm{OH}, 1: 1\right)$ and $\mathrm{RP}-\mathrm{C} 18\left(\mathrm{CH}_{3} \mathrm{OH}-\mathrm{H}_{2} \mathrm{O}, 50: 50 \rightarrow 100: 0\right)$ to obtain five fractions (Fr.A-8-1-a-Fr.A-8-1-e). Fr.A-8-1-a (56.0 mg) was purified by semipreparative HPLC $\left(\mathrm{CH}_{3} \mathrm{CN}-\right.$ $\mathrm{H}_{2} \mathrm{O}, 18: 82$ ) to yield compound $\mathbf{9}$ (1.7 $\mathrm{mg}$ ) and compound $\mathbf{1 1}$ (3.5 mg). Fr.A-8-1-b (14.7 mg) was separated by semipreparative HPLC eluted with a gradient of $\mathrm{CH}_{3} \mathrm{CN}-\mathrm{H}_{2} \mathrm{O}(28: 72 \rightarrow$ 35:65) to afford compound $\mathbf{1 0}$ (3.0 mg). Fr.A-9 (1.3 g) was chromatographed over Sephadex LH-20 $\left(\mathrm{CH}_{2} \mathrm{Cl}_{2}-\mathrm{CH}_{3} \mathrm{OH}\right.$, $1: 1)$, followed by $\mathrm{CC}$ on RP-C18 $\left(\mathrm{CH}_{3} \mathrm{OH}-\mathrm{H}_{2} \mathrm{O}, 60: 40 \rightarrow\right.$ $90: 10)$, to give two fractions (Fr.A-9-1-Fr.A-9-2). Fr.A-9-2 ( $30.0 \mathrm{mg}$ ) was further subjected to semipreparative HPLC $\left(\mathrm{CH}_{3} \mathrm{CN}-\mathrm{H}_{2} \mathrm{O}, 25: 75\right)$ to yield compound 12 (3.0 mg). Fr.A-11 $(0.8 \mathrm{~g})$ was chromatographed on Sephadex $\mathrm{LH}-20\left(\mathrm{CH}_{2} \mathrm{Cl}_{2}-\right.$ $\mathrm{CH}_{3} \mathrm{OH}$, 1:1) to give a fraction (Fr.A-11-3). Fr.A-11-3
(125.7 mg) was separated by silica gel $\mathrm{CC}\left(\mathrm{CH}_{2} \mathrm{Cl}_{2}-\mathrm{CH}_{3} \mathrm{OH}\right.$, $100: 1 \rightarrow 10: 1)$ to obtain two fractions (Fr.A-11-3-1-Fr.A-113-2). Fr.A-11-3-1 (18.5 mg) and Fr.A-11-3-2 (35.4 mg) were further purified by semipreparative HPLC to yield compound 6 (2.0 mg) and compound 7 (11.4 mg), respectively. Fr.A-13 (3.4 g) was chromatographed over Sephadex $\mathrm{LH}-20\left(\mathrm{CH}_{2} \mathrm{Cl}_{2}-\right.$ $\left.\mathrm{CH}_{3} \mathrm{OH}, 1: 1\right)$ to produce a fraction (Fr.A-13-1), which was subjected to $\mathrm{CC}$ on $\mathrm{RP}-\mathrm{C} 18\left(\mathrm{CH}_{3} \mathrm{OH}-\mathrm{H}_{2} \mathrm{O}, 50 \% \rightarrow 100 \%\right)$ to produce three parts (Fr.A-13-1-1-Fr.A-13-1-3). Fr.A-13-1-1 (174.5 mg) and Fr.A-13-1-2 (82.7 mg) were further purified by semipreparative HPLC $\left(\mathrm{CH}_{3} \mathrm{CN}-\mathrm{H}_{2} \mathrm{O}, 70: 30\right)$ to afford compounds 1 (5.6 mg) and 4 (3.6 mg), respectively. By a similar procedure to Fr.A-13, Fr.A-14 (1.4 g) was subjected successively to CC on Sephadex LH-20 $\left(\mathrm{CH}_{2} \mathrm{Cl}_{2}-\mathrm{CH}_{3} \mathrm{OH}, 1: 1\right)$ and $\mathrm{RP}-\mathrm{C} 18\left(\mathrm{CH}_{3} \mathrm{OH}-\mathrm{H}_{2} \mathrm{O}, 50: 50 \rightarrow 90: 10\right)$, followed by semipreparative HPLC, to yield compound 5 (26.6 mg). Fr.B (6.6 g) was initially isolated by Sephadex $\mathrm{LH}-20\left(\mathrm{CH}_{2} \mathrm{Cl}_{2}-\right.$ $\left.\mathrm{CH}_{3} \mathrm{OH}, 1: 1\right)$, followed by RP-C18 eluted with $\mathrm{CH}_{3} \mathrm{CN}-\mathrm{H}_{2} \mathrm{O}$ $(20: 80 \rightarrow 70: 30)$ to yield six fractions (Fr.B-1-Fr.B-6). Fr.B-2 (107.3 mg) was chromatographed on silica gel $\mathrm{CC}\left(\mathrm{CH}_{2} \mathrm{Cl}_{2-}\right.$ $\left.\mathrm{CH}_{3} \mathrm{OH}, 60: 1,50: 1,40: 1,20: 1,10: 1\right)$ to give one fraction (Fr.B2-1), which afforded compound 8 (1.0 $\mathrm{mg}$ ) by semipreparative HPLC $\left(\mathrm{CH}_{3} \mathrm{CN}-\mathrm{H}_{2} \mathrm{O}\right.$, 48:52). Fr.D (15.0 g) was initially divided into three fractions (Fr.D-1-Fr.D-3) by CC on silica gel (PE-acetone, 5:1, 3:1, 2:1, 1:1). Fr.D-2 (5.0 g) was separated by Sephadex $\mathrm{LH}-20\left(\mathrm{CH}_{2} \mathrm{Cl}_{2}-\mathrm{CH}_{3} \mathrm{OH}, 1: 1\right)$ to give four subfractions (Fr.D-2-1-Fr.D-2-4). Fr.D-2-2 (1.0 g) was isolated into three portions (Fr.D-2-2-1-Fr.D-2-2-3) by CC on RP-C18 $\left(\mathrm{CH}_{3} \mathrm{OH}-\mathrm{H}_{2} \mathrm{O}, \quad 10: 90 \rightarrow 90: 10\right)$. Fr.D-2-2-1 (47.7 mg) was further purified by semipreparative $\mathrm{HPLC}\left(\mathrm{CH}_{3} \mathrm{CN}-\mathrm{H}_{2} \mathrm{O}\right.$, 23:77) to yield compound 2 (3.3 mg). Fr.D-3 (4.1 g) was subjected to CC on Sephadex LH-20 twice, eluted with $\mathrm{CH}_{2} \mathrm{Cl}_{2}-\mathrm{CH}_{3} \mathrm{OH}$ (1:1) to get one portion (Fr.D-3-2), which was further separated by CC on RP-C18 $\left(\mathrm{CH}_{3} \mathrm{OH}-\mathrm{H}_{2} \mathrm{O}, 10: 90\right.$ $\rightarrow 90: 10$ ) to afford four fractions (Fr.D-3-2-a-Fr.D-3-2-d). Fr. D-3-2-d (10.2 mg) was purified by semipreparative HPLC to obtain compound $\mathbf{3}$ (2.0 mg).

\section{a-Glucosidase Inhibition Assay}

The $\alpha$-glucosidase inhibitory activity was assessed with a spectrophotometric method ${ }^{8}$ using acarbose as the positive control. Sample solution with six different concentrations was preincubated with $\alpha$-glucosidase $(0.2 \mathrm{U} / \mathrm{mL}$, Sigma Chemical Co. St. Louis, Missouri, United States) in 96-well plates at $37^{\circ} \mathrm{C}$ for 10 minutes. Then the substrate 4-nitrophenyl- $\alpha$-D-glucosidase (PNPG, $100 \mu \mathrm{L}, 2 \mathrm{mmol} / \mathrm{L}$, Sigma Chemical Co., United States) was added to each well. After incubation at $37^{\circ} \mathrm{C}$ for 20 minutes, the reaction was terminated with $\mathrm{Na}_{2} \mathrm{CO}_{3}$ solution $(50 \mu \mathrm{L}, 1.06 \mathrm{~g} / 50 \mathrm{~mL}$ ). The absorbance of the system was measured at $405 \mathrm{~nm}$ using a microplate reader. The $\mathrm{IC}_{50}$ was performed in triplicate and calculated with Graphpad Prism 7.0.

\section{Results and Discussion}

\section{Structure Identification}

Compound 1 was obtained as yellow powder. The molecular formula was established as $\mathrm{C}_{25} \mathrm{H}_{26} \mathrm{O}_{8}$ according 
Table $1{ }^{1} \mathrm{H}$ NMR $(400 \mathrm{MHz})$ and ${ }^{13} \mathrm{C}$ NMR $(100 \mathrm{MHz})$ data of 1 (in acetone- $d_{6}$ )

\begin{tabular}{|l|l|l|}
\hline Position & $\delta_{\mathrm{H}}(\mathrm{in} \mathrm{Hz})$ & $\delta_{\mathrm{c}}$ \\
\hline 2 & & 92.2 \\
\hline 3 & $7.07 \mathrm{br} \mathrm{s}(\mathrm{OH})$ & 102.5 \\
\hline 4 & & 188.4 \\
\hline $4 \mathrm{a}$ & & 100.8 \\
\hline 5 & $11.77 \mathrm{~s}(\mathrm{OH})$ & 164.4 \\
\hline 6 & $5.80 \mathrm{~s}$ & 90.7 \\
\hline 7 & & 171.6 \\
\hline 8 & & 106.9 \\
\hline $8 \mathrm{a}$ & & 159.5 \\
\hline $9 \mathrm{a}$ & $3.13 \mathrm{dd}(14.8,9.2)$ & 32.1 \\
\hline $\mathrm{b}$ & $2.82 \mathrm{dd}(14.8,6.0)$ & \\
\hline 10 & $5.24 \mathrm{br} \mathrm{t}(7.6)$ & 119.0 \\
\hline 11 & & 136.6 \\
\hline 12 & $1.51 \mathrm{~s}$ & 25.9 \\
\hline 13 & $1.61 \mathrm{~s}$ & 18.1 \\
\hline 14 & $3.04 \mathrm{~d}(8.4)$ & 26.5 \\
\hline 15 & $4.77 \mathrm{br} \mathrm{t}(8.4)$ & 93.2 \\
\hline 16 & & 71.5 \\
\hline 17 & $1.23 \mathrm{~s}$ & 25.9 \\
\hline 18 & $1.22 \mathrm{~s}$ & 25.2 \\
\hline $1^{\prime}$ & & 121.3 \\
\hline $2^{\prime}$ & & 161.3 \\
\hline $3^{\prime}$ & $6.39 \mathrm{~d}(2.0)$ & 99.5 \\
\hline $4^{\prime}$ & $8.72 \mathrm{br} \mathrm{s}(\mathrm{OH})$ & 161.3 \\
\hline $5^{\prime}$ & $6.52 \mathrm{dd}(8.4,2.0)$ & 109.8 \\
\hline $6^{\prime}$ & $7.36 \mathrm{~d}(8.4)$ & 125.8 \\
\hline & & \\
\hline & & \\
\hline
\end{tabular}

to the $[\mathrm{M}-\mathrm{H}]^{-}$ion peak at $m / z 453.1555$ (calcd. for $\mathrm{C}_{25} \mathrm{H}_{25} \mathrm{O}_{8}$, 453.1549) in its HRESIMS (high-resolution electrospray ionization mass spectrometry) spectrum. UV absorption maxima of compound 1 were recorded at 235 (sh), 285 (sh), and $310 \mathrm{~nm}$, indicating the presence of a sanggenontype flavanone framework (3-hydroxy-2-prenylflavanones with a furan moiety between the $B$ and $C$ rings) in this compound. ${ }^{9}$ Besides, IR spectrum of compound 1 showed the existence of $\mathrm{OH}\left(3,395 \mathrm{~cm}^{-1}\right), \mathrm{C}=\mathrm{O}\left(1,657 \mathrm{~cm}^{-1}\right)$, and benzene ring $\left(1,608\right.$ and $\left.1,463 \mathrm{~cm}^{-1}\right)$. Furthermore, the ${ }^{1} \mathrm{H}$ NMR spectrum of compound $\mathbf{1}$ ( - Table $\mathbf{1}$ ) showed (1) the signals of a hydrogen-bonded hydroxy group at $\delta_{\mathrm{H}} 11.77(1 \mathrm{H}$, br s, OH5); (2) an aromatic ABX spin system at $\delta_{\mathrm{H}} 7.36(1 \mathrm{H}, \mathrm{d}$, $\left.J=8.4 \mathrm{~Hz}, \mathrm{H}-6^{\prime}\right), 6.52\left(1 \mathrm{H}, \mathrm{dd}, J=8.4,2.0 \mathrm{~Hz}, \mathrm{H}-5^{\prime}\right)$, and $6.39\left(1 \mathrm{H}, \mathrm{d}, J=2.0 \mathrm{~Hz}, \mathrm{H}-3^{\prime}\right) ;(3)$ an aromatic proton at $\delta_{\mathrm{H}}$ $5.80(1 \mathrm{H}, \mathrm{s}, \mathrm{H}-6)$; and (4) a characteristic isoprenyl of sanggenon-type flavanone at $\delta_{\mathrm{H}} 5.24(1 \mathrm{H}$, br $\mathrm{t}, J=7.6 \mathrm{~Hz}$, $\mathrm{H}-10$ ), 3.13 (1H, br dd, J=14.8, 9.2 Hz, H-9a), 2.82 (1 H, br dd, $J=14.8,6.0 \mathrm{~Hz}, \mathrm{H}-9 \mathrm{~b}), 1.61$ (3H, br s, H-13), and 1.51 (3H, br s, $\mathrm{H}-12){ }^{7}$ In addition, signals of another cyclized isoprenyl group were observed at $\delta_{\mathrm{H}} 4.77(1 \mathrm{H}, \mathrm{br} \mathrm{t}, J=8.4 \mathrm{~Hz}, \mathrm{H}-15)$, $3.04(2 \mathrm{H}, \mathrm{br} \mathrm{d}, \mathrm{J}=8.4 \mathrm{~Hz}, \mathrm{H}-14), 1.23$ (3H, s, H-17), and 1.22 (3H, s, H-18). A total of 25 carbon signals appeared in the ${ }^{13} \mathrm{C}-$ NMR spectrum ( - Table $\mathbf{1}$ ), including 20 carbon signals from the sanggenon skeleton and 5 carbon signals from the substituent. The key HMBC correlations of $\mathrm{H}_{2}-9$ to $\mathrm{C}-3$ and $\mathrm{C}-1$ ' assigned the isoprenyl group at $\mathrm{C}-2$, confirming the sanggenon skeleton of $\mathbf{1}$. The $\mathrm{HMBC}$ correlations from $\mathrm{H}_{2-}$ 14 to $\mathrm{C}-8 \mathrm{a}$ and $\mathrm{C}-16$, and from $\mathrm{H}-15$ to $\mathrm{C}-7, \mathrm{C}-17$, and $\mathrm{C}-18$ indicated that the cyclized isoprenyl group was fused at $\mathrm{C}-7$ and $\mathrm{C}-8$. Thus, its planar structure was established as shown in - Fig. 1. Furthermore, the absolute configurations of C-2 and $\mathrm{C}-3$ in $\mathbf{1}$ were assigned as $2 R$ and $3 S$ respectively, according to the positive Cotton effects at 219, 251, 296, and $317 \mathrm{~nm}$, and negative Cotton effects at 239 and $276 \mathrm{~nm}$ in its circular dichroism (CD) spectrum ${ }^{10}$ (see - Supplementary Figs. S1, 52, s3, 54, 55, s6 [online only]). The absolute configuration of $\mathrm{C}-15$ remained to be determined. Therefore, compound 1 was elucidated as $(6 \mathrm{a} S, 11 \mathrm{~b} R)-6 \mathrm{a}, 11 \mathrm{~b}-$ dihydro5,6a,9-trihydroxy-2-(1-hydroxy-1-methylethyl)-11b-(3methyl-2-buten-1-yl)-1H,2H,6H-benzofuro[3,2-b]pyrano [2,3-e]-[1]benzofuro-6-one, and was named nigragenon $\mathrm{F}$.

The structures of the remaining 11 compounds (Fig. 1) were elucidated as trans-resveratrol (2), ${ }^{11}(E)$-4-isopentenyl-3,5,2', $4^{\prime}$-tetrahydroxystilbene $(\mathbf{3}),{ }^{12}$ notabilisin E (4), ${ }^{13}$ notabilisin A (5), ${ }^{11}$ morusin $(\mathbf{6}),{ }^{14}$ petalopurpurenol (7), ${ }^{15}$ 8-geranyl-5,7-dihydroxycoumarin (8), ${ }^{16}$ 2,4-dihydroxybenzaldehyde $(\mathbf{9}),{ }^{17}$ 4-ethoxy-2,6-dihydroxybenzoic acid (10), ${ }^{18}$ 3-hydroxy-4-methoxybenzaldehyde (11), ${ }^{19}$ and 4hydroxybenzaldehyde $(\mathbf{1 2})^{20}$ by comparing their ${ }^{1} \mathrm{H}$ and ${ }^{13} \mathrm{C}$ NMR spectral data with those reported in the literature. Compound 10 was a new natural product, and 3, 4, 7, and 8 were reported from the Morus genus for the first time.

Compound 1, nigragenon F, yellow powder; $[\alpha]^{25}{ }_{D}+66.9$ (c 0.23, MeOH); UV $\lambda_{\max }(\mathrm{MeOH})(\log \varepsilon) 210$ (3.03), 235 (sh) (1.32), 285 (sh) (3.09), $310(4.94) \mathrm{nm} . \mathrm{CD}(\mathrm{MeOH}) \lambda_{\max }(\Delta \varepsilon)$ 219 (+2.31), 239 (-0.03), $251(+0.57), 276(-0.38), 296$ $(+0.72), 317(+0.75) \mathrm{nm}$; IR (KBr) $\mathrm{v}_{\max } 3395,2925,1657$, $1622,1608,1463,1378,1149 \mathrm{~cm}^{-1} ;{ }^{1} \mathrm{H}$ and ${ }^{13} \mathrm{C}$ NMR data, see -Table 1. Negative ion HRESIMS $m / z$ : $453.1555[\mathrm{M}-\mathrm{H}]$ (calcd. for $\mathrm{C}_{25} \mathrm{H}_{25} \mathrm{O}_{8}, 453.1549$ ).

Compound 10, 4-ethoxy-2,6-dihydroxybenzoic acid, yellow-brown powder; MS (ESI) m/z: 197.04 [M - H] , molecular formula: $\mathrm{C}_{9} \mathrm{H}_{10} \mathrm{O}_{5} ;{ }^{1} \mathrm{H}-\mathrm{NMR}\left(400 \mathrm{MHz}, \mathrm{CD}_{3} \mathrm{COCD}_{3}\right) ; \boldsymbol{\delta}_{\mathrm{H}} 10.01$ (2H, br s, OH-2/6), 5.93 (2H, s, H-3/5), 4.56 (2H, q, $J=7.2$, $7.2 \mathrm{~Hz}, \mathrm{H}-7), 1.44$ (3H, t, $J=7.2 \mathrm{~Hz}, \mathrm{H}-8) ;{ }^{13} \mathrm{C}-\mathrm{NMR}(100 \mathrm{MHz}$, $\left.\mathrm{CD}_{3} \mathrm{COCD}_{3}\right) ; \delta_{\mathrm{C}} 169.9(\mathrm{C}-9), 164.8(\mathrm{C}-4), 163.0(\mathrm{C}-2 / 6), 95.5(\mathrm{C}-$ 3/5), 93.3 (C-1), 62.1 (C-7), 13.7 (C-8).

\section{a-Glucosidase Activity Screening}

Compounds 1-12 were evaluated for their $\alpha$-glucosidase inhibitory activity. All of them were initially tested for their inhibitory rates at the concentration of $100 \mu \mathrm{mol} / \mathrm{L}$. Preliminary result showed that compounds 3-8 exhibited obvious inhibitory effect with inhibition rates of more than $90 \%$, while the rest of the compounds with inhibition rates of below $50 \%$. Then, $\mathrm{IC}_{50}$ values of 3-8 were further determined. They showed potent inhibitory activities with $\mathrm{IC}_{50}$ values 

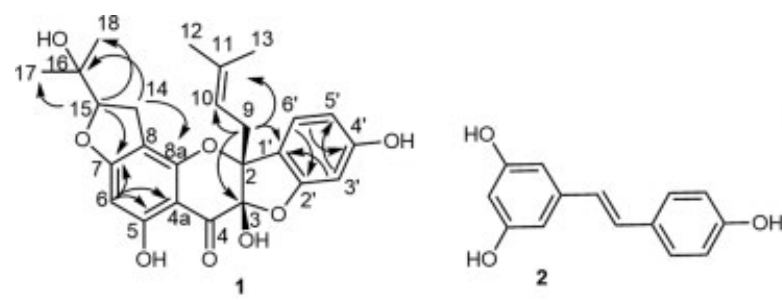<smiles>CC(C)=CCc1c(O)cc(/C=C/c2ccc(O)cc2O)cc1O</smiles><smiles>CC(C)=CCCC1(C)Oc2c(O)ccc3c2C(OC1O)C(O)C(O)C3</smiles><smiles></smiles><smiles>CCOc1cc(O)c(C(=O)O)c(O)c1</smiles><smiles>COc1ccc(C=O)cc1O</smiles><smiles>CC(C)=CCC/C(C)=C/Cc1c(O)cc(O)c2ccc(=O)oc12</smiles>

Fig. 1 Structures of compounds 1-12 isolated from M. nigra.

Table 2 The $\alpha$-glucosidase inhibitory activities

\begin{tabular}{|l|l|}
\hline Compounds & $\mathrm{IC}_{50}(\mu \mathrm{mol} / \mathrm{L})^{\mathrm{a}}$ \\
\hline 1 & - \\
\hline 2 & - \\
\hline 3 & $19.00(17.49-20.45)$ \\
\hline 4 & $1.72(1.43-2.09)$ \\
\hline 5 & $1.24(1.19-1.27)$ \\
\hline 6 & $4.72(4.01-5.91)$ \\
\hline 7 & $4.38(2.35-5.80)$ \\
\hline 8 & $12.01(11.88-13.40)$ \\
\hline 9 & - \\
\hline 10 & - \\
\hline 11 & - \\
\hline 12 & - \\
\hline Acarbose ${ }^{\mathrm{b}}$ & $987.90(874.70-1041.20)$ \\
\hline
\end{tabular}

${ }^{\mathrm{a}} \mathrm{C}_{50}$ was afforded with confidence interval $(n=3)$ and adopted $95 \%$ confidence interval; “-”: $I C_{50}>100 \mu \mathrm{mol} / \mathrm{L}$.

bPositive control.

ranging from 1.24 to $19.00 \mu \mathrm{mol} / \mathrm{L}$ (-Table 2). Of these, compound 5 showed the highest $\alpha$-glucosidase inhibitory effect with $\mathrm{IC}_{50}$ value of $1.24 \mu \mathrm{mol} / \mathrm{L}$, approximately 800 times stronger than the positive control drug acarbose.

\section{Conclusion}

In the present study, phytochemistry investigation on the stems of $M$. nigra afforded 12 compounds (1-12), including a new sanggenon-type flavanone, a new natural product, and four compounds firstly reported from the Morus genus. The $\alpha$-glucosidase inhibitory effect test provided different struc- ture-type $\alpha$-glucosidase inhibitors from $M$. nigra, not only enriching the library of natural $\alpha$-glucosidase inhibitors, but also laying experimental basis for the development and utilization of $M$. nigra as hypoglycemic medicinal plant resources.

\section{Funding}

This work was supported by the Natural Science Foundation of Shanghai (Grant No.19ZR1454400), the National Natural Science Foundation of China (Grant No. 81803844), and the National Science and Technology Major Project (Grant No. 2018ZX09731-016).

\section{Conflict of Interest}

The authors declare no conflict of interest.

\section{Reference}

1 Zhang MQ. Isolation, Purification and Characterization of $\alpha-$ Glucosidase Inhibitors from Sargassum fusiforme. [in Chinese]. Jiangsu: Jiangnan University; 2020

2 Li Y, Sun B, Hu X, et al. Research and development progress on the synthesized utilization of mulberry. [in Chinese].North Sericulture 2009;30(03):12-15

3 Jiang NZ, Bo M, Wu ZP, Tan JZ. The advancement of lowering blood glucose studies on mulberry pharmaceutical resources. [in Chinese]. Jiangsu Sericulture 2005;(04):1-4

4 Lu H, Ding TL, Wu SG, et al. The medicinal value of Xinjiang black mulberry and its application in Uighur medicine. [in Chinese]. Can Ye Ke Xue 2011;37(06):1098-1101

$5 \mathrm{Hu} \mathrm{X}, \mathrm{Wu}$ JW, Zhang XD, et al. Isoprenylated flavonoids and adipogenesis-promoting constituents from Morus nigra. J Nat Prod 2011;74(04):816-824

6 Xu L, Huang T, Huang C, Wu C, Jia A, Hu X. Chiral separation, absolute configuration, and bioactivity of two pairs of flavonoid enantiomers from Morus nigra. Phytochemistry 2019;163:33-37

$7 \mathrm{Xu} \mathrm{L}$, Yu M, Niu L, et al. Phenolic compounds isolated from Morus nigra and their $\alpha$-glucosidase inhibitory activities. Nat Prod Res 2020;34(05):605-612 
8 Wei Q Ji XY, Xu F, Li QR, Yin H. Chemical constituents from leaves of Hibiscus syriacus and their $\alpha$-glucosidase inhibitory activities [in Chinese]. Zhong Yao Cai 2015;38(05):975-979

9 Fukai T, Pei YH, Nomura T, Xu CQ, Wu LJ, Chen YJ. Isoprenylated flavanones from Morus cathayana. Phytochemistry 1998;47(02): 273-280

10 Shi YQ, Fukai T, Ochiai M, Nomura T. Absolute structures of 3hydroxy-2-prenylflavanones with an ether linkage between the 2 '- and 3-positions from moraceous plants. Heterocycles 2001;55 (01):13-20

11 Sivakumar B, Murugan R, Baskaran A, Khadangale BP, Murugan S, Senthilkumar UP. Identification and characterization of processrelated impurities of trans-resveratrol. Sci Pharm 2013;81(03): 683-695

12 Jayasinghe ULB, Puvanendran S, Hara N, Fujimoto Y. Stilbene derivatives with antifungal and radical scavenging properties from the stem bark of Artocarpus nobilis. Nat Prod Res 2004;18(06):571-574

$13 \mathrm{Hu} \mathrm{X}$, Ji J, Wang M, et al. New isoprenylated flavonoids and adipogenesis-promoting constituents from Morus notabilis. Bioorg Med Chem Lett 2011;21(15):4441-4446
14 Nomura T, Fukai T, Yamada S, et al. Phenolic constituents of the cultivated mulberry tree (Morus alba L.). Chem Pharm Bull (Tokyo) 1976;24:2898-2900

15 Huang L, Fullas F, McGivney RJ, et al. A new prenylated flavonol from the root of Petalostemon purpureus. J Nat Prod 1996;59(03): 290-292

16 Sarker SD, Armstrong JA, Gray AI. Sesquiterpenyl coumarins and geranyl benzaldehyde derivatives from the aerial parts of Eriostemon myoporoides. Phytochemistry 1994;37(05):1287-1294

17 Zheng ZP, Xu Y, Qin C, et al. Characterization of antiproliferative activity constituents from Artocarpus heterophyllus. J Agric Food Chem 2014;62(24):5519-5527

18 Maruyama S, Kaneko Y. 4-Alkoxy-3,5-dihalo-2,6-dihydroxybenzoic acids. Ger Offen; 1969

19 Bi D, Xia G, Li Y, Liang X, Zhang L, Wang L. Two new cassane diterpene lactams from the fruits of Caesalpinia mimosoides Lam. Nat Prod Res 2018;32(08):875-879

20 Hornung PS, Masisi K, Malunga LN. Natural bioactive starch film from Amazon turmeric (Curcuma longa L.). Polym Bull 2018;75 (10):4735-4752 